\title{
Surface modification of titanium alloy by anodic oxidation method to improve its biocompatibility
}

\author{
Anil Kumar ${ }^{1, *}$ and Manoj Kumar Kushwaha ${ }^{2}$ \\ ${ }^{1}$ I. K. Gujral Punjab Technical University, Jalandhar 144 603, India \\ ${ }^{2}$ Department of Mechanical Engineering, S.B.S. State Technical Campus, Ferozepur 152 004, India
}

Surface modification of titanium alloy (Ti-6Al-4V) has been performed by anodic oxidation method within various concentration ranges of sulphuric acid $\left(\mathrm{H}_{2} \mathrm{SO}_{4}\right)$ electrolyte. It describes the oxidation kinetics of the anodizing process and critical analysis of process parameters like concentration of electrolyte, voltage, time and anodic current density, was performed to obtain homogenized nano-sized porous structure on the titanium substrate. XRD (X-ray diffraction technique) and FE-SEM (field emission scanning electron microscopy) were utilized for phase analysis as well as for morphological survey. XRD report revealed that porous structure appeared at $0.4 \mathrm{M}$ concentration of the electrolyte and at anodic voltage of $20 \mathrm{~V}$. Anatase to rutile phase transformation was observed at $0.5 \mathrm{M}$ of $\mathrm{H}_{2} \mathrm{SO}_{4}$. Tribological test of anodized as well as nonanodized surface performed on pin-on-disc type tribometer suggested that anodized surface possessed high wear resisting strength compared to bare metal surface. The present study tries to enhance the biocompatible features especially bone cell attachment or cell proliferation of titanium alloy by improved surface characteristics.

Keywords: Anodic oxidation, FE-SEM, tribometer, X-ray diffraction.

TITANIUM, due to its remarkable mechanical, optical, chemical or biomedical properties has large area of applications. Due to its prominent properties of adequate biocompatibility and osseointegration, it is widely used in biomedical engineering generally in dental implantation and orthopaedic surgery ${ }^{1}$. Despite this, their long term uses create complications like loosening of implants due to wear and also infections in some cases. Thus before using titanium or its alloys as a biomaterial, the surface of the implants should be improved by anodization ${ }^{2}$, ultra violet assisted technique (UVA) ${ }^{3}$, along with improved cell proliferation and bone cell attachment property ${ }^{4}$. It has been observed that application of titanium for a long time or say continuous service of implants releases harmful ions specially vanadium ions in case of titanium grade

\footnotetext{
*For correspondence. (e-mail: mr.anilsuthar@rediffmail.com)
}

5 which may spoil tissues or react with blood cells. This tissue spoilage creates various health problems like Alzheimer's disease, neuropathy and osteomalacia ${ }^{5}$. Improved metal extraction technique and determination of new alloys provide advanced generation of biomaterials, titanium-copper alloy (above $5 \%$ by wt.) which makes it more suitable as an implant since the antimicrobial properties of copper resist bacterial growth. Also, addition of copper with titanium enhances eutectoid in grain boundaries and facilitates improved surface hardness ${ }^{6}$.

Normally, various techniques are available to fabricate nano-structured surfaces, for instance, alkaline treatment ${ }^{7}$, anodization $^{8}$, laser treatment ${ }^{9}$ and sandblasting acidetching ${ }^{10}$. Minagar et al. ${ }^{11}$ suggested that fine porous surface and pore morphology are essential requirements for growth of new tissues when anodized titanium plate is implanted in human body by surgery. Tissue proliferation mainly correlated with inorganic phase grain size, gives an acceptable range of grain size which is 10 to $50 \mathrm{~nm}$ in immature bone and of 20 to $50 \mathrm{~nm}$ in matured bones respectively ${ }^{12}$.

Moreover, microscale nano-porous structure resolves such critical issues observed after surgery including aseptic loosening, periprosthetic fractures, instability and infections. Several researches reported that micro and nano-textured implants surface have adequate level of interfacial bonding stamina ${ }^{13}$. Generally, nanoscale surface topography is very useful for reduction of bacterial adhesion. Despite this, reduction of bacterial adhesion by formulation of nano-porous surface ( $80 \mathrm{~nm}$ range) is an issue of controversy ${ }^{14}$. Number of methods and techniques were utilized from time to time to improve anticorrosion strength, biocompatibility and mechanical properties of titanium and its alloys. Aniolek et al. ${ }^{15}$ reported that very fine nano-porous oxide surface was formulated by thermal oxidation process $\left(600^{\circ} \mathrm{C}\right.$ to $800^{\circ} \mathrm{C}$ and time duration: $20 \mathrm{~min}$ to $72 \mathrm{~h}$ ) and phase transformation from anatase to rutile at $800^{\circ} \mathrm{C}$ which offers 1.6 times antiwear strength compared to bare metal surface.

Critical study of literature ${ }^{16-30}$ makes it easier to choose a suitable and economical method among various alternative ways to achieve nano-porous like surface illustrated as anodization technique, alkaline treatment, and 
Table 1. Details of anodization process parameters

\begin{tabular}{|c|c|c|}
\hline Parameter & Specimen $1\left(\mathrm{~S}_{1}\right)$ & Specimen $2\left(\mathrm{~S}_{2}\right)$ \\
\hline Electrolyte molarities $\left(\mathrm{H}_{2} \mathrm{SO}_{4}\right)$ & $0.5 \mathrm{M}-4.0 \mathrm{M}$ & $1 \mathrm{M}$ \\
\hline Anodic voltage $(\mathrm{V})$ & $10-90 \mathrm{~V}$ & $15 \mathrm{~V} \succ$ (optimum) \\
\hline Time $(\mathrm{sec})$ & 300 & 300 \\
\hline Temperature (K) & $298 \mathrm{~K}$ (room temperature) & $298 \mathrm{~K}$ (room temperature) \\
\hline Agitation & Mechanical stirrer & Mechanical stirrer \\
\hline
\end{tabular}

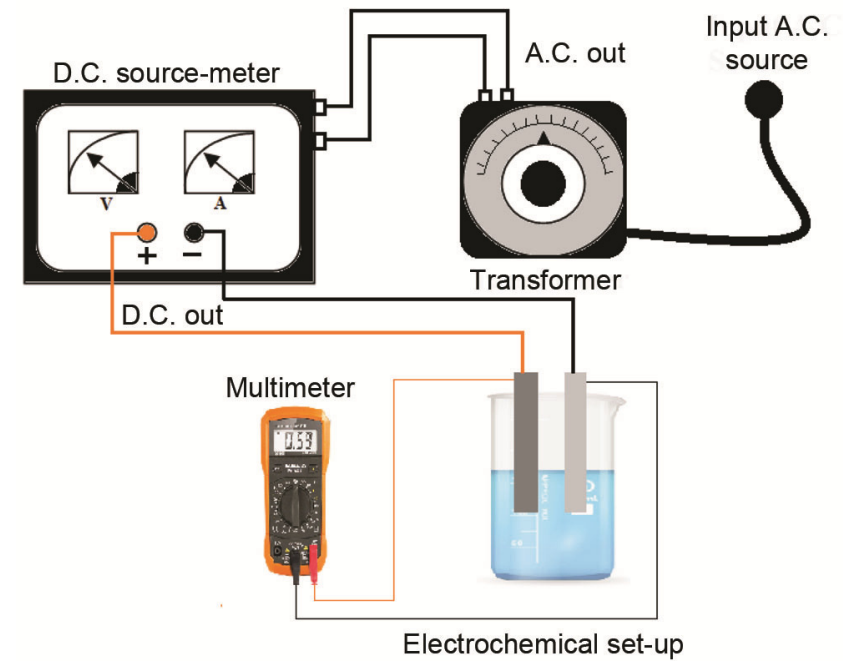

Figure 1. Set-up used for electrochemical process.

thermal oxidation method, etc. while for the selection of biomaterial, our focus should be to analyse mechanical and chemical attributions, surface morphology, tribological behaviour of the nanopore surface to improve proliferation, osseointegration and reliability.

\section{Experiment}

\section{Pre-treatments}

Ti-6Al-4V termed as titanium grade five alloy possessing a chemical composition of $5.7<\mathrm{Al}<6.5 \%, 3.8<\mathrm{V}<$ $4.3 \%$ and titanium as remainder, was selected as substrate material. Energy dispersive spectroscopy (EDS) equipped with SEM was utilized to determine the composition of constituents in titanium specimen. Two types of specimens adopted for anodization have same composition but differ in size specially thickness. First sample was tagged as $\mathrm{S}_{1}(100 \mathrm{~mm} \times 300 \mathrm{~mm} \times 0.4 \mathrm{~mm}$ sheet $)$ and second $(10 \mathrm{~mm} \times 10 \mathrm{~mm}$, with convenient thickness $)$ as $\mathrm{S}_{2} . \mathrm{S}_{2}$ was used to determine oxide film hardness only, since $S_{1}$ was not convenient to measure appropriate indentation on thin oxide surface. Specimen surface $\left(\mathrm{S}_{1}\right.$ and $\left.\mathrm{S}_{2}\right)$ was polished properly by silicon carbide paper (300 to 1500 grit) to remove foreign materials deposited on the sample surface like sand, grease/oil, paint marks and natural oxide film. Polished specimens were dipped in ethanol bath followed by acetone bath for $5 \mathrm{~min}$ each. After soaking specimens, pickling was performed within a mixture of $\mathrm{HNO}_{3}(25 \mathrm{wt} \%)$ and $\mathrm{HF}(5 \mathrm{wt} \%)$ at room temperature for $15 \mathrm{~min}$ to obtain adequate surface finish like a mirror (60 $\mathrm{nm}$ approximately).

\section{Anodization kinetics}

Coupons of size $20 \mathrm{~mm} \times 100 \mathrm{~mm} \times 0.4 \mathrm{~mm}$ were cut from $\mathrm{S}_{1}$, and an area of $1 \mathrm{sq} . \mathrm{cm}(10 \mathrm{~mm} \times 10 \mathrm{~mm})$ was exposed to electrolyte for each specimen during anodization and the remaining portion was insulated by lacquer (adhesive paint). Small sized coupons were anodized within sulphuric acid electrolyte by an EC (electrochemical) cell equipped with agitator and thermometer. Titanium foil was connected with positive point and termed as anode while counter electrode of commercial pure aluminium was made cathode by connecting with negative point of DC power source (Figure 1). Time to allow the flow of current through the circuit was $300 \mathrm{sec}$. Electrolytic concentration range adopted for anodization was $0.5 \mathrm{M}$ to $4 \mathrm{M}$, and the solution was diluted by mixing deionized water in concentrated sulphuric acid of specific gravity 1.84 . Voltage range of $10-80 \mathrm{~V}$ was adopted for anodization and the operating parameters are provide in Table 1. After EC reaction, samples were rinsed in double deionized water. Stirrer was deputed to dissipate heat evolved during the chemical reaction. Thermometer was monitored continuously during anodization to maintain a specific temperature of electrolyte and to retain solution homogeneity in the cell. $S_{2}$ was anodized by identical equipments as adopted for $\mathrm{S}_{1}$ but only at optimum values of process parameters, depicted in Table 1.

\section{Characterization of samples}

Anodized sample of area 1 sq. $\mathrm{cm}$ was placed on pin mount specimen holder succeeded by coating a thin layer of gold on bared sample to allow electrical conductivity between the specimen and the specimen carrier, and placed in a vacuum chamber to evaluate surface characteristics. German made Ultra Plus (ZEISS) FE-SEM equipped with EDS was utilized for morphological investigation of anodized and nontreated surface by capturing high quality images from 1000 to $10000 \times$ magnification. BRUKER 
(D-8, ADVANCE) XRD was used for phase identification of anodized titanium oxide film surface. Surface roughness of the polished sample surface as well as that of the anodized sample surface, was determined through WYKO made (NT-1100) optical profilometer (interfaced with Vision ${ }^{\circledR} 32$ software) in terms of Ra. Finally, Vicker's microhardness tester (401 MVD) was utilized to differentiate anodized surface and nonanodized sample surface. $50 \mathrm{~g}$ to $500 \mathrm{~g}$ indenter load was applied to determine the surface hardness of the sample and care should be taken that indenter does not go beneath the oxide layer to obtain precise and accurate surface hardness value. Five indentations were marked by applying a load for $20 \mathrm{sec}$ on the sample to determine an average value of hardness. Dry test was performed on pin-on disc type tribometer (TR-20LE, DUCOM) and graph plotted with WINDUCOM software. Refer Table 2 for wear test parameters.

\section{Results and discussions}

\section{Titanium oxidation kinetics}

Number of experiments were performed to determine the effects of operating parameters on oxide deposition.

Table 2. Wear test parameters

\begin{tabular}{ll}
\hline Parameter & \multicolumn{1}{c}{ Value } \\
\hline Disc speed & $300 \mathrm{rpm}$ \\
Load & $3 \mathrm{~kg}$ or $29.43 \mathrm{~N}$ \\
Track diameter & $100 \mathrm{~mm}$ \\
Time & $180 \mathrm{sec}$ \\
Disc material & Hardened steel \\
\hline
\end{tabular}

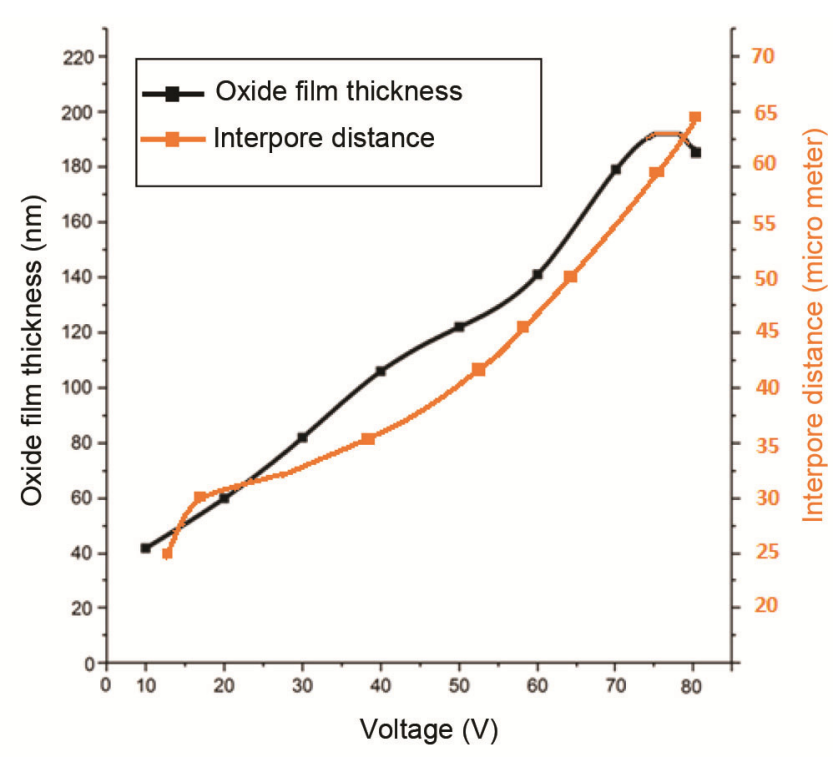

Figure 2. Process voltage, oxide film thickness and inter-pore distance relationship, at $1 \mathrm{M}: \mathrm{H}_{2} \mathrm{SO}_{4}$, time: $300 \mathrm{sec}$.
Voltage effect was determined initially and other parameters such as electrolytic concentration, solution temperature and process time remained constant. Cell potential varied from 10 to $90 \mathrm{~V}$ with an incremental change of $10 \mathrm{~V}$ in each segment. For each concentration of electrolyte, nine experiments were performed. EC reaction proceeds immediately when current flows throw the circuit or with immersion of specimen within the electrolyte. It has been observed that oxide deposition rate was vibrant initially but the increment resisted the electrons flow through the circuit and deposition rate became reduced. Oxide film thickness increased significantly with inter-pore distance caused by increase in voltage which supports fast oxide deposition which in turn supports significant incremental change in inter-pore distance. Voltage, oxide layer thickness, and pore density/interpore distance justify this statement as observed in Figure 2. It was observed that further increase in anodic voltage resulted in oxide layer dissolution and breakdown in oxide deposition.

The next most influencing parameter is concentration of electrolyte. A suitable range of electrolyte was $0.5 \mathrm{M}$ to $5 \mathrm{M}$ of sulphuric acid whereas first sample was anodized at $0.5 \mathrm{M}$, second at $1 \mathrm{M}$, third sample at $1.5 \mathrm{M}$ and so on. Accordingly, a total of eight solution samples were prepared for anodization. Very fine homogeneous porous structure was observed when seen through SEM for each electrolyte concentration level, as explained in the following morphological analysis section. Concentrated electrolyte offers poor surface roughness when used for anodization. Bar diagram in Figure 3 clarifies this process.

Above discussed experimental exercises were performed at optimum value of voltage $(15 \mathrm{~V})$ for each sample. Because this optimized anodic voltage provide very fine pore structure, uniform oxide deposition rate was sustained.

\section{Phase analysis}

X-ray diffraction (XRD) pattern shown in Figure 4 reported phase transformation for the anodized sample. XRD profiles were observed for electrolytic molarities from $0.5 \mathrm{M}-3 \mathrm{M}$, for a process time of $300 \mathrm{sec}$, voltage $15 \mathrm{~V}$ and performed at room temperature. Phase analysis was conducted schematically at a constant angle of incidence say $2 \theta$. Abscissa showed that the peak intensity of the substrate reduced when the concentration of $\mathrm{H}_{2} \mathrm{SO}_{4}$ increased at $2 \theta=40.2^{\circ}$. XRD also reported that the oxide film thickness increased with electrolyte's concentration. Higher peak value attained by rutile was $116\left(2 \theta=36.5^{\circ}\right)$, observed at $2.5 \mathrm{M}$ of $\mathrm{H}_{2} \mathrm{SO}_{4}$. Instant dominated oxide phase transformation was observed from anatase to rutile when molar concentration crossed a value of $0.5 \mathrm{M}$. XRD revealed that cell potential and electrolytic concentration 


\section{RESEARCH ARTICLES}

both affect crystal structure and it was clearly observed that both these parameters altogether lead amorphous to crystal formation i.e. anatase to rutile formation (Table 3).

\section{SEM/morphological analysis}

Aesthetical change was observed immediately with the immersion of specimen in EC cell. While the circuit was completed, oxygen evolved at anode combined with $\mathrm{Ti}$ ion to build up titanium oxide $\left(\mathrm{TiO}_{2}\right)$ layer.

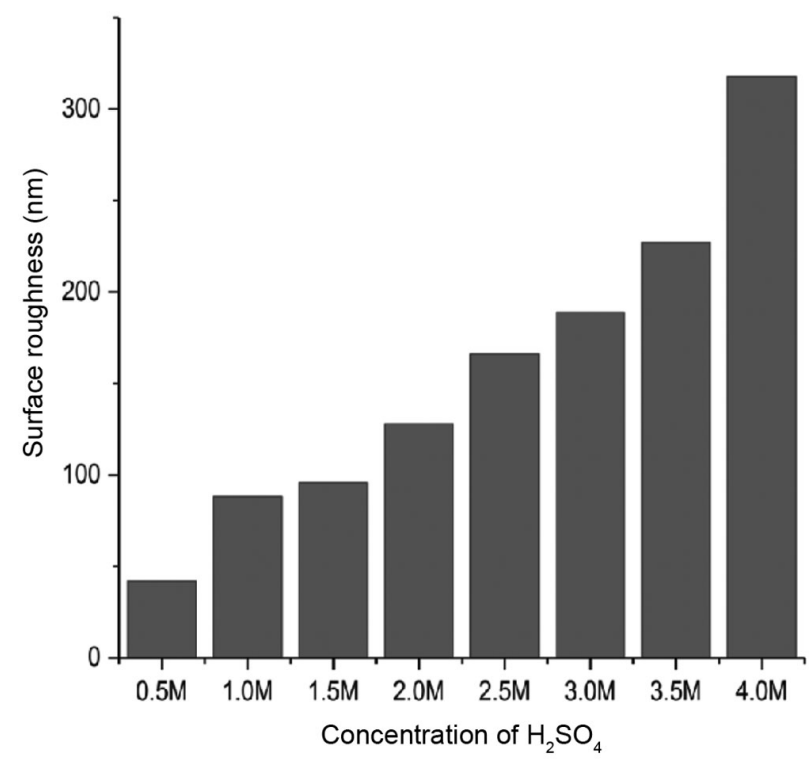

Figure 3. Electrolyte concentration versus surface roughness relation.

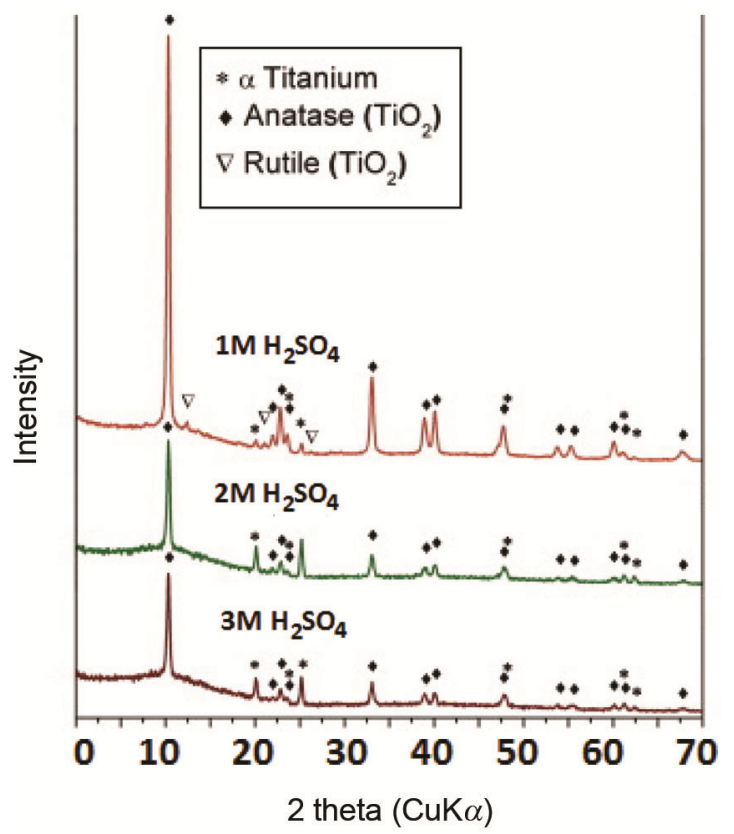

Figure 4. X-ray diffraction profiles of an anodized sample.
Colourful patterns or shades were obtained during EC reaction. This physical change was observed on the surface of the specimen while anodization was caused by variation in process voltage at a consistent level of solution concentration. The observed colourful shades are not dyes or pigments as it is only the phenomenon of light. Thickness of the anodized $\mathrm{TiO}_{2}$ (ATO) was measured by SEM. A specially designed aluminium fixture was used to hold the specimen for SEM test, Figure $5 a$ shows drawing of fixture and Figure $5 b$ shows the position of clamped sample. Both the ends of the sample were bent at $180^{\circ}$; due to this the oxide film cracked and utile
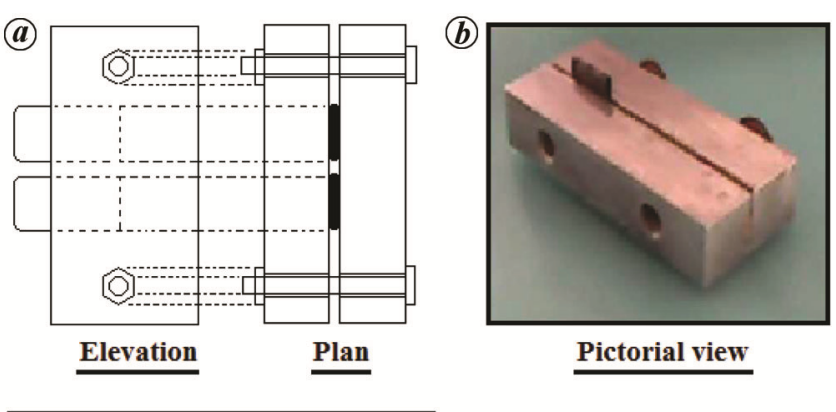

Pictorial view

(c) Direction of view

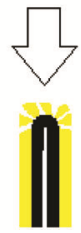

Figure 5. Specially designed fixture to quantify ATO thickness where $(\boldsymbol{a})$ shows drawing of the fixture, and $(\boldsymbol{b})$ represents the direction of observation during SEM test and $(\boldsymbol{c})$ is the pictorial view of the same.

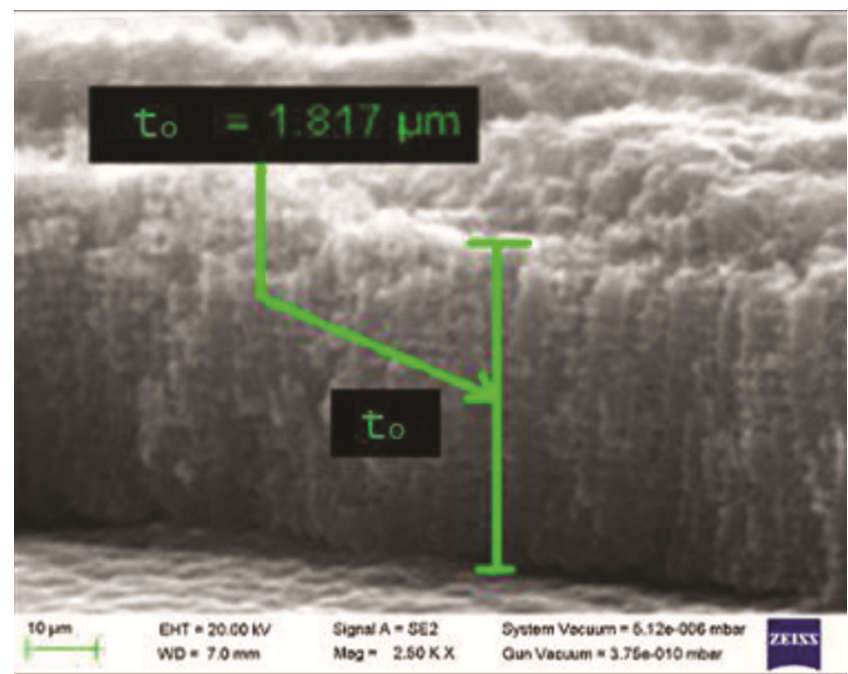

Figure 6. Scanning electron microscopy (SEM) image of the anodized sample $\left(\mathrm{Ti}_{6} \mathrm{Al}_{4} \mathrm{~V}\right)$ shows the maximum value of oxide film thickness at various operating parameters, viz. voltage: $60 \mathrm{~V}$, electrolytic concentration: $1 \mathrm{M}$ of $\mathrm{H}_{2} \mathrm{SO}_{4}$ 
Table 3. Oxide phases report

\begin{tabular}{lccc}
\hline & \multicolumn{3}{c}{ Molar concentration $\left(\mathrm{H}_{2} \mathrm{SO}_{4}\right)$} \\
\cline { 2 - 4 } Material & $>0.5 \mathrm{M}$ & $0.5-2.5 \mathrm{M}$ & $<2.5 \mathrm{M}$ \\
\hline Titanium (grade-5) & $\mathrm{TiO}_{2}$ (anatase) & $\mathrm{TiO}_{2}$ (rutile) peak & $\mathrm{TiO}_{2}$ (rutile) dull \\
\hline
\end{tabular}
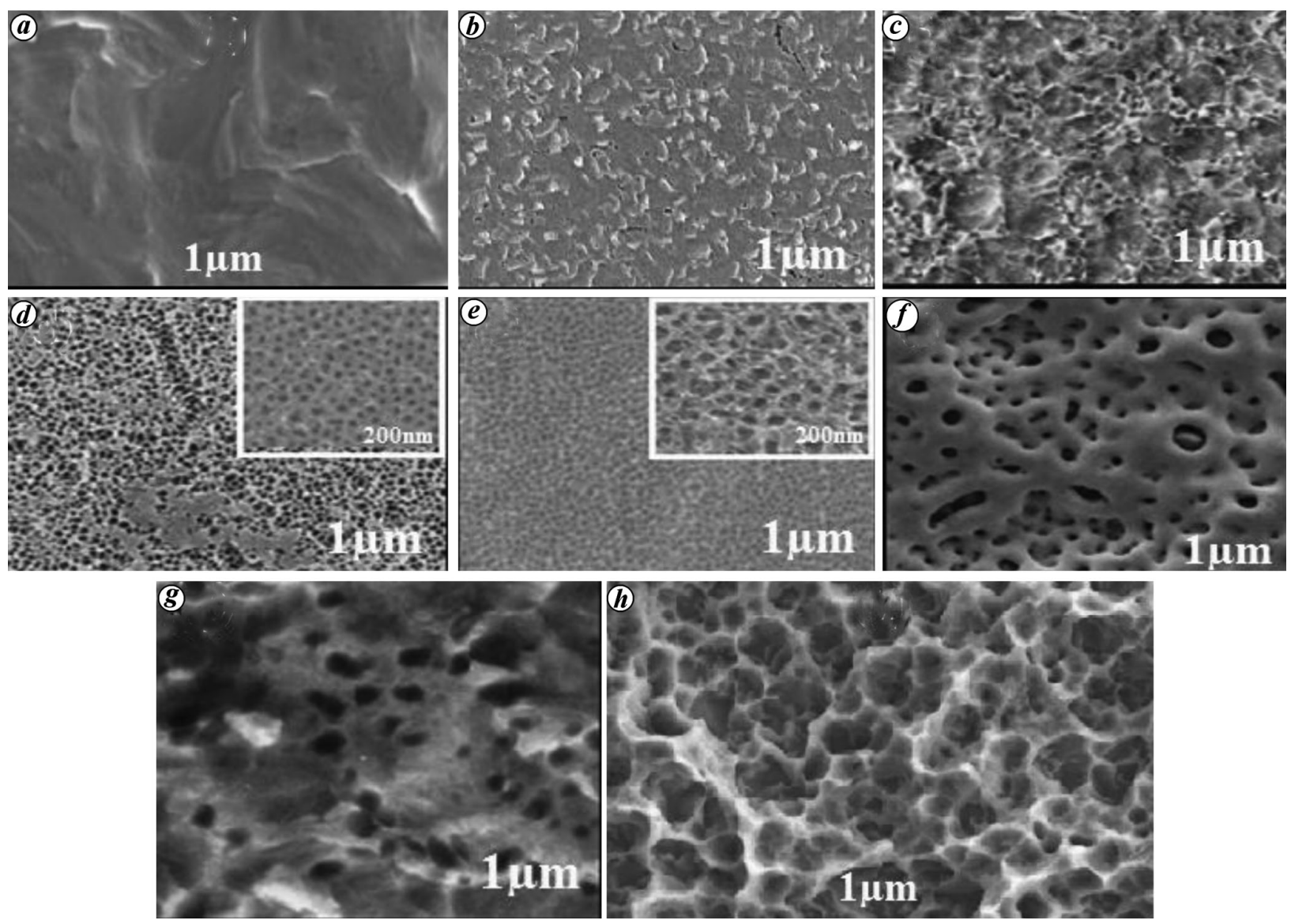

Figure 7. SEM micrographs. $\boldsymbol{a}$, Titanium substrate used for anodization. $\boldsymbol{b}, \boldsymbol{c}, \mathrm{TiO}_{2}$ at $10 \mathrm{~V}$ and $20 \mathrm{~V}$ respectively and at $0.5 \mathrm{M}$ concentration of electrolyte and $(\boldsymbol{d}-\boldsymbol{h})$ at $30 \mathrm{~V}, 40 \mathrm{~V}, 50 \mathrm{~V}, 60 \mathrm{~V}$ and $80 \mathrm{~V}$ respectively, and at $1 \mathrm{M}$ concentration of $\mathrm{H}_{2} \mathrm{SO}_{4}$. ( $1 \mu \mathrm{m}$ scale used for each sample).

cavities were fabricated up to extremity of the layer. When charged particles emitted through SEM were made to fall on the turned surface of the sample, a clear image of the oxide film thickness appeared which was suitable to evaluate the ATO thickness. The cross-sectional area of the oxide film is shown in Figure 6.

Figure 7 represents SEM micrographs of porous oxide surfaces obtained when titanium substrate was anodized at optimum parameters, as in Table 1. Pore diameter change was observed with change in value of anodizing parameters. A critical SEM analysis report was prepared systematically on the basis of micrographs captured for each sample. For a concentration range of $0.5 \mathrm{M}$ to $4 \mathrm{M}$ and voltage range from $10 \mathrm{~V}$ to $90 \mathrm{~V}$, such selected images were placed and exhibited, where, in each segment, increase in anodic voltage provided an incremental change in pore diameters, porosity and oxide layer thickness. Figure 7 shows a total of eight images: (a) polished surface before anodization, ( $b$ to h) anodized sam- ple micrographs. Evaluation report observed after SEM analysis is shown in Table 4 which helps to recognize the effect of anodization parameters on morphology of the anodized film. Below 0.4 M concentration of electrolyte reduces and faded oxide film deposition occurs.

On the other hand it has been observed that oxide deposition rate increases linearly with increase in voltage, but porous structures do not appear below $0.4 \mathrm{M}$. When the concentration of a solution crossed a value of $0.5 \mathrm{M}$, nano-porous like structure emerged on the substrate. Uniform change in surface morphology was observed when $1 \mathrm{M}$ of sulphuric acid was utilized at $10-15 \mathrm{~V}$ of anodic potential, very fine nano-sized pore structures emerged (Figure $7 d$ ). After crossing a value of $15 \mathrm{~V}$ for $1 \mathrm{M}$ of solution, concentration homogeneity vanishes as well as diameter starts increasing vigorously. From these observations it is evident that the concentrated electrolyte supports change in surface morphology and further increase in the concentration, remove chances of 

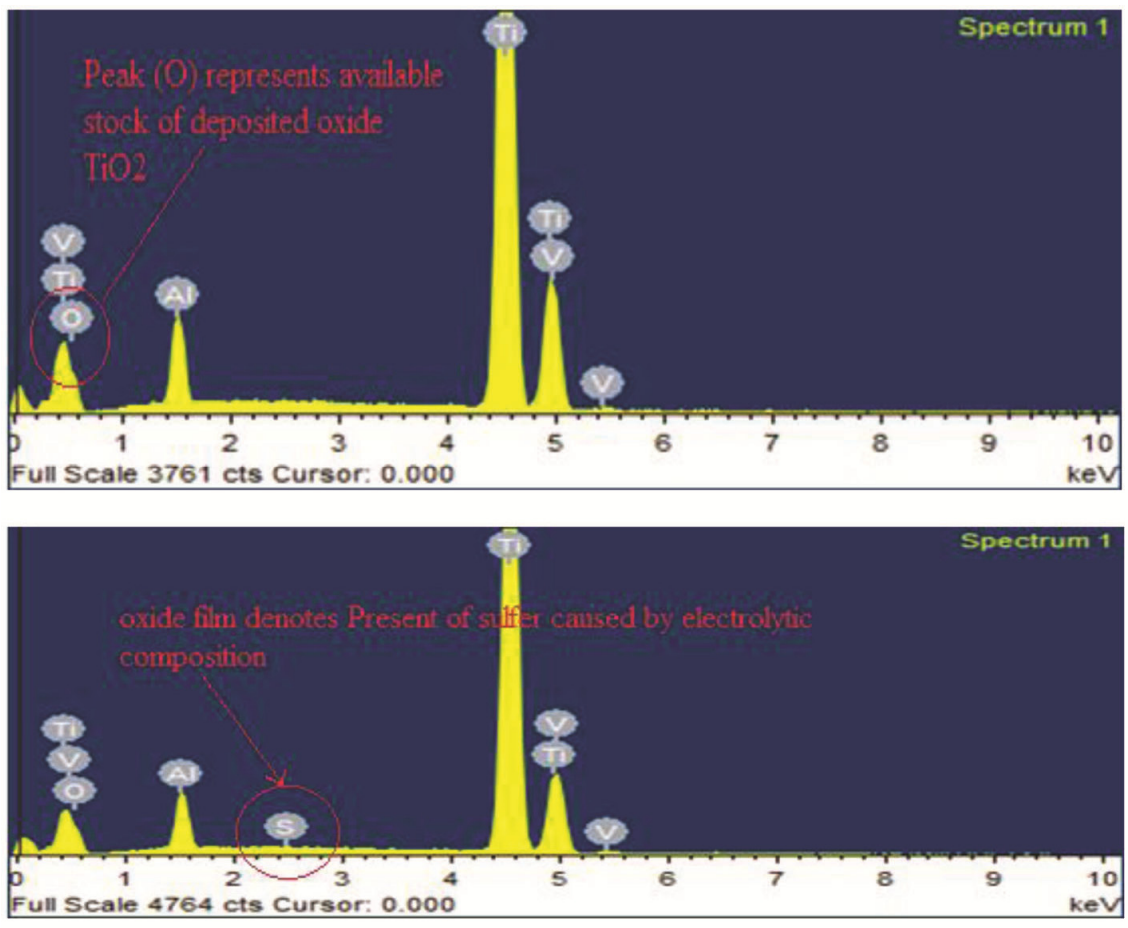

Figure 8. Energy dispersive spectroscopy analysis represents deposited oxide composition.
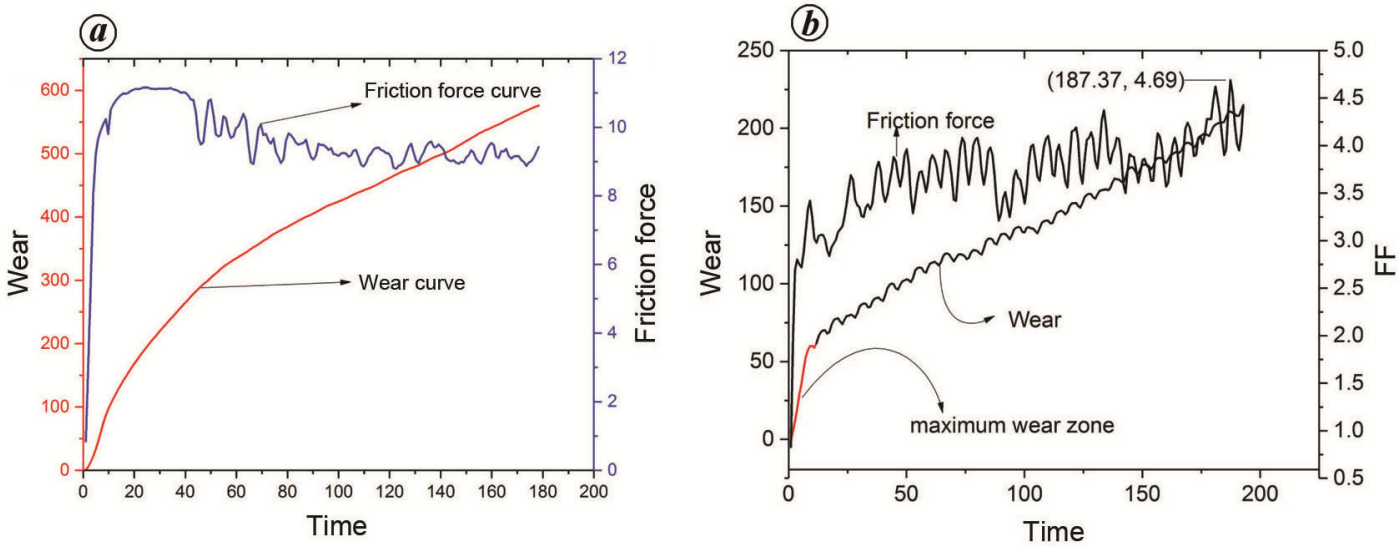

Figure 9. Wear or friction force (FF) versus time relationship for non-anodized (a) and anodized samples (b). Maximum wear determined in nonanodized sample was $\approx 600 \mu \mathrm{m}$, whereas for anodized face it was less than $250 \mu \mathrm{m}$. Respective FF scatter repeat same relationship correspondingly.

nano-porous structure formation. For $1 \mathrm{M}$ of electrolytic concentration and voltage of $80 \mathrm{~V}$, oxide dissolution occurred (Figure $7 \mathrm{~h}$ ).

EDS test reported that maximum availability of each constituent is represented by peak value. First image of Figure 8 shows the composition of oxygen element available in the oxide film deposited on titanium surface, while the second image in the Figure 8 shows the elemental composition of titanium specimen used for anodization.

Tribology test of an anodized sample was performed on pin-on-disc type tribometer and a comparative report was obtained for both anodized and non-anodized samples. Parameters adopted for wear test are indicated in
Table 2. Corrugation wear was observed on the surface of non-anodized sample in the form of wide pits and traces. Anodized specimen was fixed on steel disc which allowed to rotate at specified RPM whereas a copper pin was slid over the rotating sample's surface. While performing wear test it is important to maintain the position of the specimen or to say anodized face should be positioned between pin and steel disc properly and should not have any relative motion with the pin. To achieve this high quality adhesive was used. It was observed that the anodized titanium sample possessed high anti wear strength compared to non-treated surface (Figure 9). Thus nano-porous oxide film deposited through anodization improves anti fade quality of the surface while in 

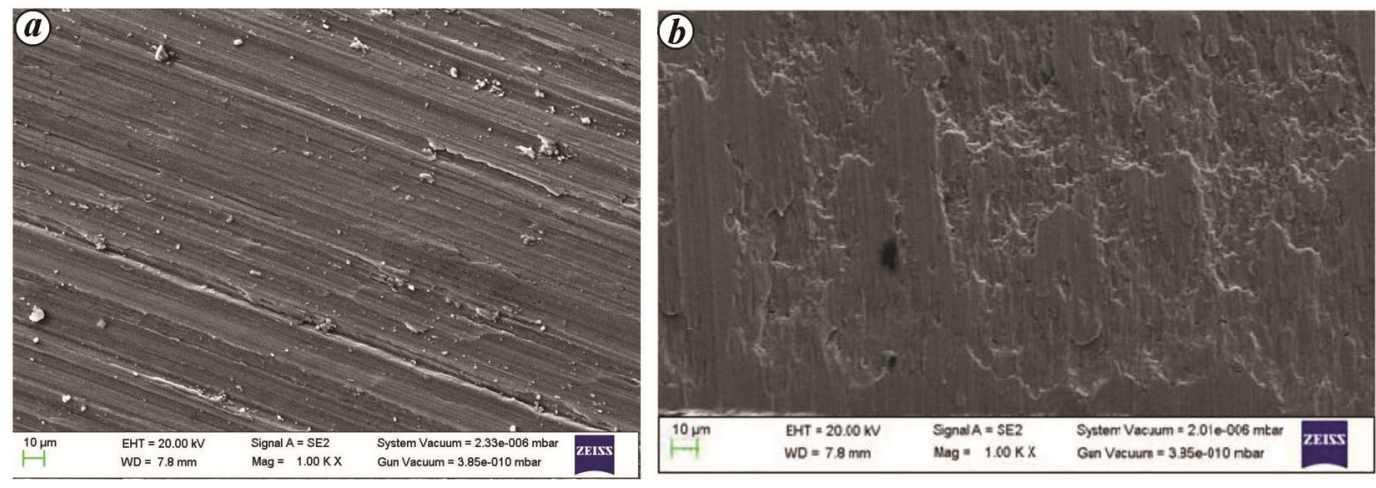

Figure 10. SEM image analysis of worn-out surfaces of $(\boldsymbol{a})$ anodized and $(\boldsymbol{b})$ non-anodized specimen after the wear test.

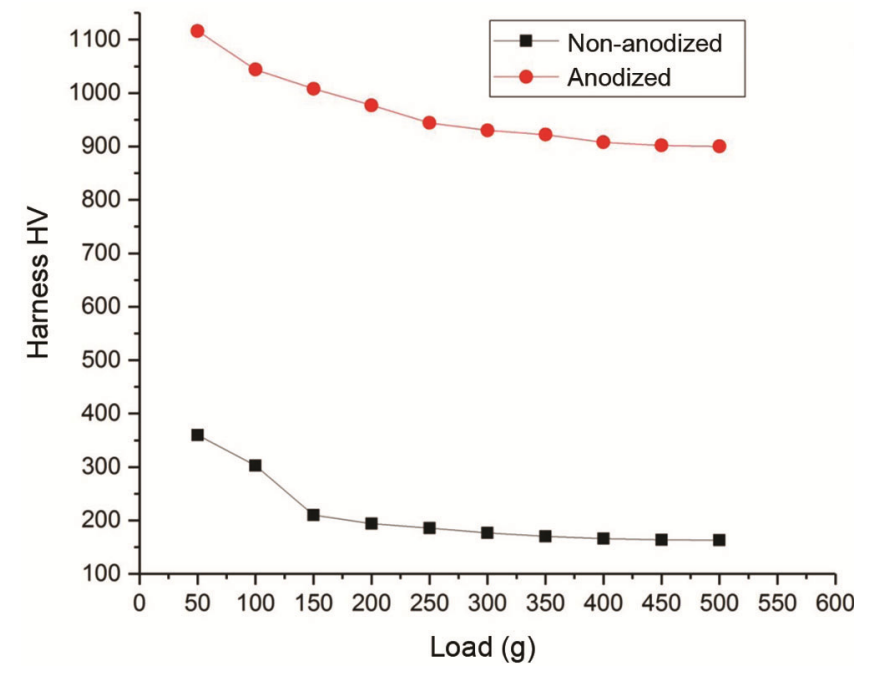

Figure 11. Hardness test for an anodized and non-anodized sample.

Table 4. Geometrical parameters obtained after anodization

\begin{tabular}{lccc}
\hline Voltage & Pore diameter & Inter-pore distance & Porosity \\
\hline 10 & 0.871 & 23.5 & 35 \\
20 & 1.250 & 28.7 & 48 \\
30 & 1.785 & 29.2 & 44 \\
40 & 1.840 & 34.5 & 51 \\
50 & 2.220 & 37.6 & 54 \\
60 & 2.432 & 44.4 & 61 \\
70 & 2.666 & 54.8 & 69 \\
80 & 2.894 & 70.4 & 77 \\
\hline
\end{tabular}

mechanical application where metal to metal contact takes place. SEM micrographs shown in Figure $10 a$ and $b$ revealed that the oxide film was not completely exhausted during wear test. Thus the initial frictional difference in the run-in period is an indication of the evolution of conformity between the surfaces.

After wear test, SEM test was performed for worn out samples and it was observed that the oxide layer was not completely exhausted in case of anodized sample (Figure $10 a$ ), whereas in case of non-anodized surface comparatively more wear took place (Figure $10 b$ ). Thus SEM report after wear test confirmed that the anodized sample results showed better performance compared to bare titanium substrate during mechanical application especially for tribological application.

Micro-hardness test (indicated in Figure 11) was performed on $\mathrm{S}_{2}$, and a diamond shaped indenter with load range of 50-500 $\mathrm{g}$ was used to mark an indent on the surface of the specimen over a time span of $20 \mathrm{sec}$. Three indentations were marked on the specimen for a particular value of load and then its average value was determined. Initially unstable value of hardness was observed for both anodized and non-anodized samples because of the involvement of larger measurement characteristics over smaller load (50-100 g) and of small indenter size. But when the indenter load increased from $100 \mathrm{~g}$ and reached its maximum value of $500 \mathrm{~g}$, the hardness curve became stable. A maximum of $360 \mathrm{HV}$ was determined for non-anodized sample whereas in case of anodized surface hardness approached to $1116 \mathrm{HV}$. Thus hardness test performed on Vicker's micro-hardness tester exhibited that anodized surface offered more surface hardness and resisted scratches and indents formation compared to non-anodized titanium substrate.

\section{Conclusion}

This study provides the technique to improve the surface characteristics of a biomaterial and elaborate its predominant properties illustrated as cell proliferation and osseointegration. From the analysis conducted following conclusions can be formulated:

(i) SEM analysis revealed to establish an optimum value of parameters like anodic voltage $(15 \mathrm{~V})$ and $(1 \mathrm{M})$ electrolytic concentration, which would be ideal to achieve a fine and homogeneous nano-porous oxide surface which is the key requirement for the biomaterial to resist bacterial growth and make it more reliable for a long term usage.

(ii) It is observed that when voltage exceeds $10 \mathrm{~V}$, the homogeneity improved continuously, but will be lost when voltage approaches $20 \mathrm{~V}$. To obtain a fine 


\section{RESEARCH ARTICLES}

nano-porous surface with tremendous homogeneity, anodization at $15 \mathrm{~V}$ was performed which justified the statement that $15 \mathrm{~V}$ is an optimum voltage to obtain a precise nano-porous surface.

(iii) It can be concluded that when our aim is to have amorphous to crystalline phase transformation, then sulphuric acid is an optimal electrolyte for anodization.

(iv) Voltage is observed as the most effective parameter among other anodization parameters. Even a small change in voltage can be detected easily in the form of aesthetic as well as morphological change. Pore diameter, pore density and homogeneity of the porous structure depend strongly on process voltage.

(v) Anodization is an easy and economical process to improve tribological properties as well as surface hardness of the titanium or its alloy which enhances their mechanical, optical, aeronautical and medical applications.

1. Gugelmin, B. S. and Araujo Ponte, H. D., Electrochemical stability and bioactivity evaluation of $\mathrm{Ti}_{6} \mathrm{Al}_{4} \mathrm{~V}$ surface coated with thin oxide by EIS for biomedical applications. Mater. Res., 2015, 18(3), 602-607.

2. Gao, A., Hang, R., Bai, L., Tang, B. and Chu, P. K., Electrochemical surface engineering of titanium-based alloys for biomedical application. Electrochim. Acta, 2018, 271, 699-718.

3. Lee, T. C., Abdullah, H. Z., Koshy, P. and Idris, M. I., Ultravioletassisted biomimetic coating of bone-like apatite on anodised titanium for biomedical applications. Thin Solid Films, 2018, 660, 191-198.

4. Mohammed, M. T., Development of a new metastable beta titanium alloy for biomedical applications. Karbala Int. J. Mod. Sci., 2017, 3(4), 224-230.

5. Pina, V. G., Amigó, V. and Muñoz, A. I., Microstructural, electrochemical and tribo-electrochemical characterisation of titaniumcopper biomedical alloys. Corros. Sci., 2016, 109, 115-125.

6. Nag, S., Banerjee, R. and Fraser, H. L., Microstructural evolution and strengthening mechanisms in $\mathrm{Ti}-\mathrm{Nb}-\mathrm{Zr}-\mathrm{Ta}, \mathrm{Ti}-\mathrm{Mo}-\mathrm{Zr}-\mathrm{Fe}$ and Ti-15Mo biocompatible alloys. Mater. Sci. Eng. C, 2005, 25(3), 357-362.

7. Wei, M., Kim, H. M., Kokubo, T. and Evans, J. H., Optimising the bioactivity of alkaline-treated titanium alloy. Mater. Sci. Eng. C, 2002, 20(1-2), 125-134.

8. Kulkarni, M., Mazare, A., Schmuki, P., Iglič, A. and Seifalian, A., Biomaterial surface modification of titanium and titanium alloys for medical applications. Nanomedicine, 2014, 111, 111-135.

9. Zhang, R., Wan, Y., Ai, X., Men, B., Wang, T., Liu, Z. and Zhang, D., Fabrication of micro/nano-textured titanium alloy implant surface and its influence on hydroxyapatite coatings. J. Wuhan Univ. Technol.-Mater. Sci. Ed., 2016, 31(2), 440-445.

10. Orsini, G., Assenza, B. and Antonio, S., Surface analysis machined versus sand blasted and aci-etched titanium implants. Int. J. Oral Max. Impl., 2000, 15, 779-784.

11. Minagar, S., Wang, J., Berndt, C. C., Ivanova, E. P. and Wen, C., Cell response of anodized nanotubes on titanium and titanium alloys. J. Biomed. Mater. Res. Part A, 2013, 101(9), 2726-2739.

12. Jayaraman, M., Meyer, U., Bühner, M., Joos, U. and Wiesmann, H. P., Influence of titanium surfaces on attachment of osteoblastlike cells in vitro. Biomaterials, 2004, 25(4), 625-631.

13. Sykaras, N., Iacopino, A. M., Marker, V. A., Triplett, R. G. and Woody, R. D., Implant materials, designs, and surface topogra- phies: their effect on osseointegration. A literature review. Int. J. Oral Max. Impl., 2000, 15(5), 675-690.

14. Ercan, B., Taylor, E., Alpaslan, E. and Webster, T. J., Diameter of titanium nanotubes influences anti-bacterial efficacy. Nanotechnology, 2011, 22(29), 295102.

15. Aniołek, K., Kupka, M., Barylski, A. and Dercz, G., Mechanical and tribological properties of oxide layers obtained on titanium in the thermal oxidation process. Appl. Surf. Sci., 2015, 357, 14191426.

16. Sharma, A. K., Anodizing titanium for space applications. Thin Solid Films, 1992, 208(1), 48-54.

17. Diamanti, M. V. and Pedeferri, M. P., Effect of anodic oxidation parameters on the titanium oxides formation. Corros. Sci., 2007, 49(2), 939-948.

18. Fan, M. and La Mantia, F., Effect of surface topography on the anodization of titanium. Electrochem. Comm., 2013, 37, 91-95.

19. Wu, L., Wen, C., Zhang, G., Liu, J. and Ma, K., Influence of anodizing time on morphology, structure and tribological properties of composite anodic films on titanium alloy. Vacuum, 2017, 140, 176-184.

20. Karambakhsh, A., Afshar, A. and Malekinejad, P., Corrosion resistance and color properties of anodized Ti-6Al-4V. J. Mater. Eng. Perform., 2012, 21(1), 121-127.

21. Mingthong, P., Veerasai, W. and Aeimbhu, A., Fabrication of Titanium oxide nanotube arrays on titanium implants: the effect of electrolytes conditions. In 6th World Congress of Biomechanics (WCB 2010), 1-6 August 2010, Singapore, Springer, Berlin, Heidelberg, 2010, pp. 1208-1211.

22. Masahashi, N., Mizukoshi, Y., Semboshi, S. and Ohtsu, N., Enhanced photocatalytic activity of rutile $\mathrm{TiO}_{2}$ prepared by anodic oxidation in a high concentration sulfuric acid electrolyte. Appl. Catal. B: Environ., 2009, 90(1-2), 255-261.

23. Bloyce, A., Qi, P. Y., Dong, H. and Bell, T., Surface modification of titanium alloys for combined improvements in corrosion and wear resistance. Surf. Coat. Technol., 1998, 107(2-3), 125-132.

24. Hang, R., Liu, Y., Bai, L., Zhang, X., Huang, X., Jia, H. and Tang, B., Length-dependent corrosion behavior, $\mathrm{Ni}^{2+}$ release, cytocompatibility, and antibacterial ability of $\mathrm{Ni}-\mathrm{Ti}-\mathrm{O}$ nanopores anodically grown on biomedical NiTi alloy. Mater. Sci. Eng. C, 2018, 89, $1-7$.

25. Hatem, A., Lin, J., Wei, R., Torres, R. D., Laurindo, C., de Souza, G. B. and Soares, P., Tribocorrosion behavior of low friction TiSiCN nanocomposite coatings deposited on titanium alloy for biomedical applications. Surf. Coat. Technol., 2018, 347, 1-12.

26. Shang, Y. and Sui, L., State of osseointegrated titanium implant surfaces in topographical aspect. J. Nanosci. Nanotechnol., 2018, 18(12), 8016-8028.

27. Kumar, S., Narayanan, T. S., Raman, S. G. S. and Seshadri, S. K., Thermal oxidation of $\mathrm{Ti}_{6} \mathrm{Al}_{4} \mathrm{~V}$ alloy: microstructural and electrochemical characterization. Mater. Chem. Phys., 2010, 119(1-2), 337-346.

28. Krishna, D. S. R., Brama, Y. L. and Sun, Y., Thick rutile layer on titanium for tribological applications. Tribol. Int., 2007, 40(2), 329-334.

29. Kuromoto, N. K., Simão, R. A. and Soares, G. A., Titanium oxide films produced on commercially pure titanium by anodic oxidation with different voltages. Mater. Character., 2007, 58(2), 114-121.

30. Luz, A. R., de Souza, G. B., Lepienski, C. M., Siqueira, C. J. and Kuromoto, N. K., Tribological properties of nanotubes grown on Ti-35Nb alloy by anodization. Thin Solid Films, 2018, 660, 529537.

Received 7 March 2019; revised accepted 11 November 2020

doi: $10.18520 /$ cs/v120/i5/907-914 